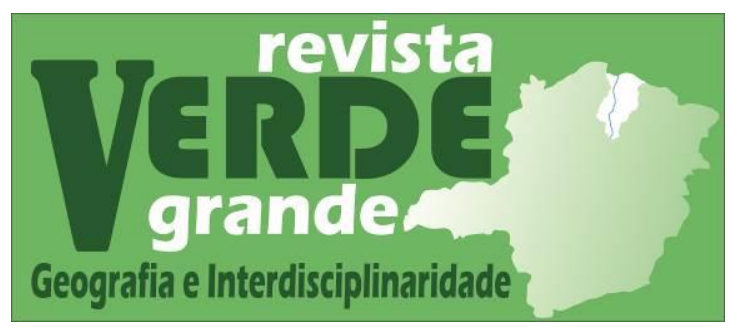

Volume 2, no. 2 (2020)

ISSN: 2675-2395

https://doi.org/10.46551/rvg26752395202027089

\title{
ENSINO DE GEOGRAFIA EM TEMPOS DE PANDEMIA: VIVÊNCIAS NA ESCOLA MUNICIPAL PROFESSOR AMÉRICO BARREIRA, FORTALEZA - CE
}

Teaching geography in pandemic times: experiences at municipal school professor Américo Barreira, Fortaleza - CE

Rebeka Carvalho Macêdo ${ }^{1}$ https://orcid.org/0000-0001-8786-5426

Kaline da Silva Moreira ${ }^{2}$ https://orcid.org/0000-0002-7476-6151

\footnotetext{
${ }^{1}$ Licenciada em Geografia - Universidade Federal do Ceará - UFC; Professora da Rede Municipal de Fortaleza. E-mail: rebekacarvalhomacedo@gmail.com

2 Mestranda em Geografia - Universidade Estadual de Montes Claros - UNIMONTES, Campus Montes Claros. E-mail: kalynemoreira@hotmail.com
}

\begin{abstract}
Resumo
No presente artigo apresentamos um estudo sobre os desafios do ensino de geografia no modelo Home Office no período de isolamento social na Escola Municipal Professor Américo Barreira localizada no Bairro Genibaú na cidade de Fortaleza - CE. Apresenta-se um estudo qualitativo de cunho descritivo e exploratório durante o período de ensino não presencial de geografia no seguimento da rede pública de ensino. A metodologia aplicada é baseada em um levantamento bibliográfico sobre as temáticas: a educação em tempos de pandemia e o ensino de geografia com o uso de tecnologias. A pesquisa foi dividida em três etapas: I) Revisão Bibliográfica; II) Prática do ensino de Geografia no modelo Home Office e aplicação de atividades como uso das Tecnologias da Informação e Comunicação; III) Análises e reflexões sobre os resultados da experiência. O principal objetivo dessa pesquisa é descrever de maneira exploratória as metodologias dos docentes de geografia e os principais desafios e mudanças em virtude da pandemia do Covid-19, apontando como resultados as reflexões das teorias versus a prática sobre o ensino de geografia no cenário pandêmico.
\end{abstract}

Palavras-chave: Ensino de Geografia, TIC'S, Home Office, Pandemia.

\begin{abstract}
In this article we present a study on the challenges of teaching geography in the Home Office model during the period of social isolation at the Municipal School Professor Américo Barreira located in the Bairro Genibaú in the city of Fortaleza - CE. A qualitative study of a descriptive and exploratory nature is presented during the period of non-classroom teaching of geography following the publicschool system. The applied methodology is based on a bibliographic survey on the themes: education in times of pandemic and the teaching of geography with the use of technologies. The research was divided into three stages: I) Bibliographic Review; II) Geography teaching practice in the Home Office model and application of activities such as the use of Information and Communication Technologies; III) Analyzes and reflections on the results of the experiment. The main objective of this research is to describe in an exploratory way the methodologies of geography teachers and the main challenges and changes due to the Covid-19 pandemic, pointing out as a result the reflections of
\end{abstract}


Ensino de Geografia em tempos de Pandemia: vivências na Escola Municipal Professor Américo Barreira, Fortaleza - CE

Rebeka Carvalho Macêdo; Kaline da Silva Moreira

theories versus the practice on teaching geography in the pandemic scenario.Keywords: Physical environment; Human occupation; Systemic analysis.

Keywords: Geography Teaching, TIC’S, Home Office, Pandemic.

\section{Introdução}

No presente trabalho procuramos abordar alguns dos principais desafios no ensino de geografia durante a Pandemia do Covid-19 (SARS-cov2). Com isso, essa pesquisa busca analisar o ensino remoto ou não presencial na Rede Pública de ensino na Escola Municipal Professor Américo Barreira localizada no Bairro Genibaú na cidade de Fortaleza - CE durante o período de isolamento social.

Para compreendermos as motivações da abordagem do ensino remoto de geografia, inicialmente apontaremos uma breve contextualização sobre a realidade da educação brasileira durante a pandemia com enfoque nas deliberações governamentais para só assim chegar nos caminhos de interesse central que são os principais desafios do ensino de geografia e as reflexões no cenário pandêmico.

Em meio a rápida corrida de instrumentalização e adaptações metodológicas e técnicas dos docentes, muitos desafios e dificuldades sobre a realidade do trabalho em Home Office ou do ensino remoto de geografia se apresentam. Faz-se necessário gerar reflexões sobre o papel do professor de geografia e suas práticas metodológicas em conformidade a Base Nacional Comum Curricular (BNCC) para realização do ensino de qualidade em tempo de isolamento social.

Entendemos que, existe uma diferença entre ensino presencial e não presencial e que por motivos de força maior por ocorrência do isolamento social ocasionado pelo vírus do Covid-19 (SARS-cov2) tendo um teor de caráter emergencial, o ensino à distância (EAD) teve que ser adaptado em todas as redes de ensino no Brasil, sendo que essa modalidade já era utilizada, mas em pouca escala no ensino básico, mas consolidada no ensino superior.

Essa diferença conceitual vem da organização dos métodos e técnicas para os desenvolvimentos das aulas adaptadas ao ensino remoto com os materiais dos próprios professores orientada por diretrizes emergenciais, diferente da aula EAD que tem toda uma lógica de preparo e realização, ensino-aprendizagem e avaliação além de uma legislação de amparo consolidada.

O ensino durante o isolamento social é considerado não presencial sendo instituído por motivos de uma crise na saúde mundial, no entanto, nada impede a implementação do ensino 
EAD dependendo da realidade escolar. Porém ambas se assemelham no quesito de que os professores e alunos mantêm interação em lugares distintos simultâneos.

Dito isso, restaram poucas alternativas para a adaptação dos professores que não sejam as ligadas as ferramentas tecnológicas e ao uso da internet para tentar manter o curso da educação. Nesta pesquisa entendemos a importância da formação continuada e optamos por desenvolver durante a pandemia, estratégias de adaptação do ensino de geografia não presencial de acordo com a realidade socioeconômica que a escola está inserida.

A pesquisa qualitativa possibilita a exploração, a descrição da complexidade do tema e o problema da investigação de forma que possa permitir ao pesquisador a análise, compreensão, classificação para a geração de contribuições aos indivíduos envolvidos e ao objeto de pesquisa (SCHNEIDER et al. 2016). Desse modo, a metodologia do estudo desenvolvida tem enfoque qualitativo por meio da análise bibliográfica de artigos científicos e descrição empírica das práticas docentes. A pesquisa é de natureza descritiva e exploratória no modelo de trabalho Home Office observando as medidas de isolamento social.

O ensino de geografia em tempos de pandemia se apresenta como um novo objeto de estudo para da ciência geográfica e amplia a nossa curiosidade sobre os efeitos e consequências nos diversos setores da sociedade, principalmente na educação.

Diante de toda essa conjuntura, surgem as seguintes problemáticas: quais são os principais desafios do ensino-aprendizagem remoto de geografia no contexto do isolamento social? Como o professor de geografia vivencia na prática a rápida instrumentalização do uso de Tecnologias Digitais da Informação e Comunicação (TIC) no ensino não presencial na rede pública?

Compreendemos por meio das problemáticas levantadas que esse é um tema de profunda relevância nacional e que ainda não é trabalhado com profundidade e a partir dessas reflexões a geografia enquanto ciência será enriquecida.

Nesse contexto, o principal objetivo dessa análise é descrever, sob a ótica da prática do docente de geografia, os principais desafios e mudanças metodológicas em virtude da pandemia do Covid-19 apontando como resultados as reflexões das aulas de geografia no cenário pandêmico.

A pesquisa foi desenvolvida em três etapas, entre as quais: I) Revisão Bibliográfica, onde foram utilizadas referências na área de Educação em tempos de Pandemia, Ensino de Geografia e o uso de TIC's; II) Planejamentos e aplicação das aulas de maneira remota descrevendo as estratégias e atividades para a realização dos alunos de maneira virtual; III) Análises e reflexões das experiências dos docentes de Geografia na Escola Municipal 
Ensino de Geografia em tempos de Pandemia: vivências na Escola Municipal Professor Américo Barreira, Fortaleza - CE

Rebeka Carvalho Macêdo; Kaline da Silva Moreira

Professor Américo Barreira considerando as dificuldades e mudanças em virtude da pandemia do Covid-19.

Sobre a estrutura deste artigo divide-se em três seções: a primeira uma breve contextualização sobre a relação da educação brasileira em tempos de pandemia e articulação dos conceitos de ensino de geografia relacionando ao uso das TIC's; a segunda como a descrição do processo de adaptação do ensino não presencial de geografia considerando o papel da gestão, docentes, discentes e a família, e por fim, a terceira seção apontando os resultados e discussões sobre a aplicabilidade das estratégias no ensino de geografia, no seguimento da rede pública de ensino na Escola Municipal Professor Américo Barreira, expondo os principais desafios e reflexões sobre o ensino de geografia dentro do contexto socioeconômico da comunidade escolar durante o período de isolamento social.

\section{Breve contextualização da educação e do ensino de geografia em tempos de pandemia}

A repercussão sobre pandemia do Covid-19 teve início no Brasil nas mídias e redes sociais em fevereiro de 2020. Segundo Portal do G1 (2020) com o constante e rápido aumento no número de caso da doença principalmente nas capitais, o Governo do Estado do Ceará e a Prefeitura de Fortaleza implementaram medidas de isolamento social por meio do DECRETO No33.519, de 19 de março de 2020, inicialmente com duração de 15 dias, para impedir atividades que geram aglomerações como medida primordial de contenção ao avanço desse vírus conhecido com Covid-19 ou Coronavírus (SARS-cov2) seguindo as recomendações da Organização Mundial de Saúde (OMS). Senhoras (2020) resume bem o processo da pandemia quando fala que:

\footnotetext{
No início do ano de 2020, a rápida difusão internacional do novo Coronavírus (2019 n-CoV) em menos de 1 mês, tendo como epicentro de propulsão da pandemia, a China, com uma centena de mortos e milhares de doentes, e mais de 20 países afetados, fez com que a OMS declarasse situação de emergência de saúde internacional, buscando engendrar diplomaticamente uma ação coordenada de impedimento ao fenômeno espontâneo e paradiplomática de propagação do vírus, bem como o combate à doença pelos Estados Nacionais. (SENHORAS, 2020).
}

A Organização Mundial de Saúde (OMS) lançou diversos vídeos, panfletos e iconográficos informativos sobre o Coronavírus para as escolas divulgarem propondo medidas para o convívio domiciliar, e distribuição da merenda das escolas públicas, atenção domiciliar para prevenção, saúde mental, seguros e conectados disponibilizado no site da OPAS Brasil.

Segundo Silva (2020) destaca que o MEC emitiu a Portaria $n^{\circ} 343$, concedendo a substituição de aulas presenciais, que estivessem ainda em andamento, por aulas utilizem de 
Ensino de Geografia em tempos de Pandemia: vivências na Escola Municipal Professor Américo Barreira, Fortaleza - CE

Rebeka Carvalho Macêdo; Kaline da Silva Moreira

meios tecnológicos, considerando o tempo que perdurar a pandemia causada pelo novo Coronavírus.

Apenas em abril de 2020, o Conselho Nacional da Educação aprovou diretrizes disponíveis no parecer CNE/CP Nº 5/2020 sobre a reoganização do calendário escolar e atividades não presenciais que foi aprovado parcialmente, posteriormente revisado em junho de 2020 e homologado sobre o parecer CNE/CP Nº 9/2020 para a educação em razão da pandemia do Covid-19 tendo o objetivo de orientar estados, municípios e escolas sobre as práticas que devem ser adotadas do ensino não presencial.

Além disso, elas propõem normas nacionais gerais para a reorganização dos calendários, que é de responsabilidade dos sistemas de ensino e sugere orientações para cada seguimento de ensino que vai desde o infantil, superior, educação indígena, quilombola, ensino de jovens e adultos (EJA) e educação especial. São apresentadas, no geral, medidas de ensino não presencial, além de indicar as famílias o papel de auxiliar os estudos nos seguimentos iniciais.

Nesse contexto, as escolas e universidades foram fechadas "Situação que obrigou as autoridades governamentais, tomar diversas ações que fossem eficazes para que houvesse um possível controle da disseminação da doença. Entre uma das medidas apresentadas, corresponde-se ao distanciamento ou ao isolamento social." (MARQUES, 2020, p. 32) dando início a um ciclo de incertezas e rapidamente as instituições e professores tiveram que adaptar mecanismo de ensino propondo diversos métodos adaptados em plataformas digitais para garantir as aulas de ensino não presencial.

Sendo assim, não existe um consenso entre as instituições da rede pública e particular de ensino nos critérios de como ensinar e por onde ensinar as disciplinas. Cada instituição busca métodos, ferramentas e plataformas que melhor se adaptam a realidade do público alvo de ensino.

Segundo Silva (2020) destaca que a própria Lei de Diretrizes e Bases da Educação Nacional (LDB- Lei $\mathrm{n}^{\circ}$ 9.394/96) dispõe sobre a possibilidade de substituir aula presencial por aulas à distância em casos de emergência. É o que prevê o art. 32, § $4^{\circ}$

$\S 4^{\circ} \mathrm{O}$ ensino fundamental será presencial, sendo o ensino a distância utilizado como complementação da aprendizagem ou em situações emergenciais. (BRASIL, 1996).

Nas escolas de Educação básica, a paralização das aulas presenciais trouxeram novos desafios à medida que as estratégias de antecipação de férias, paralisação ou continuidade das atividades por meio do EAD trouxeram impactos abruptos para professores e as famílias, à

\section{2, n.2, 2020 https://www.periodicos.unimontes.br/index.php/verdegrande}


Ensino de Geografia em tempos de Pandemia: vivências na Escola Municipal Professor Américo Barreira, Fortaleza - CE

Rebeka Carvalho Macêdo; Kaline da Silva Moreira

medida que a educação domiciliar trouxe mudanças para o aprendizado das crianças e dos jovens, eventualmente sobrecarregando os próprios pais no contexto de acompanhamento destas atividades (BURGESS et al., 2020 apud MARQUES, 2020).

Nessa perspectiva, compreende-se que a Geografia tem buscado analisar como bases preliminares o que está posto como consequências da pandemia que são amplamente debatidos nas lives e rodas de conversas virtuais como pautas de destaque da Associação dos Geógrafos Brasileiros (AGB) e das universidades e programas de pós graduação por todo Brasil.

Atualmente, o programa de pós graduação de geografia da Universidade Federal do Ceará (UFC) desenvolve um projeto de pesquisa voltado para "Dimensões essenciais da docência em situações de crise" sob a ótica da Geografia Cultural que perpassa sobres as percepções docentes no cenário da atual crise pandêmica além de outras pesquisas sobre o Covid-19.

Entendemos que há necessidade de reflexões sobre as percepções dos profissionais docentes sobre o ensino remoto de geografia. Sendo de suma importância a pesquisa de relevância para práxis do fazer docente e a troca de experiências. Visto que, se faz importante compreender como o professor de geografia vivência na prática a rápida instrumentalização do uso de Tecnologias Digitais da Informação e Comunicação (TIC), ensino não presencial e uso do ciberespaço segundo as concepções de Lévy (1999) no período de isolamento social no seguimento da educação básica e os possíveis reflexos no retorno à normalidade.

\section{O processo de adaptação ao ensino remoto na escola professor américo barreira e o uso de tecnologias}

A escola municipal Professor Américo Barreira fica situada no Bairro Parque Genibaú na cidade de Fortaleza-CE. O Parque Genibaú (Figura 1) fica localizado em Fortaleza - CE, na região oeste da cidade. O bairro é administrado pela Secretaria Executiva Regional V. Em seu entorno encontram-se os bairros Antônio Bezerra, Autran Nunes, Henrique Jorge, João XXIII, Granja Portugal, Conjunto Ceará I e Conjunto Ceará II. O bairro faz fronteira com o município de Caucaia, e tem como um de seus limites o Rio Maranguapinho. 
Ensino de Geografia em tempos de Pandemia: vivências na Escola Municipal Professor Américo Barreira, Fortaleza - CE

Rebeka Carvalho Macêdo; Kaline da Silva Moreira

Figura 1: Delimitação do Bairro Parque Genibaú e localização da escola.

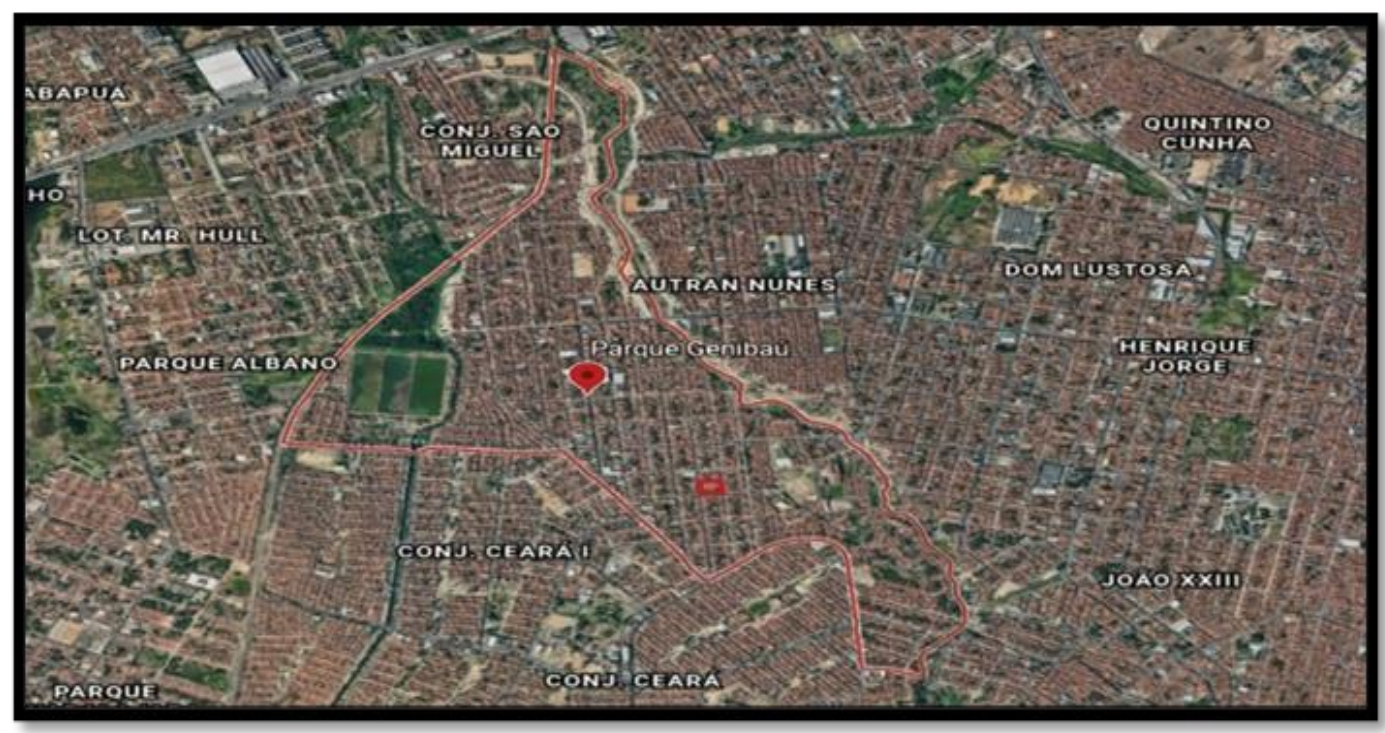

Fonte: Google Earth, 2020.

Segundo o portal da escola, a E.M Prof. Américo Barreira (Figura 2) surgiu das reivindicações dos movimentos da Associação São Gabriel e da Comunidade Religiosa Capela de São José do Parque Genibaú. Em 1993 esta escola foi fundada, porém sua inauguração se deu no dia 10 de Janeiro de 1994, na Gestão do Prefeito Dr. Antônio Elbano Cambraia e do Secretário de Educação e Cultura, Major Austhon Guilherme da Silva, tendo como patrono o Professor Américo Barreira, brasileiro, natural de Baturité - Ceará, que desde cedo se destacou e contribuiu na atividade estudantil e política cearense. Estando localizada na Rua Ricardo Pontes 529 - Bairro Parque Genibaú.

Figura 2: Frente da Escola Municipal Américo Barreira.

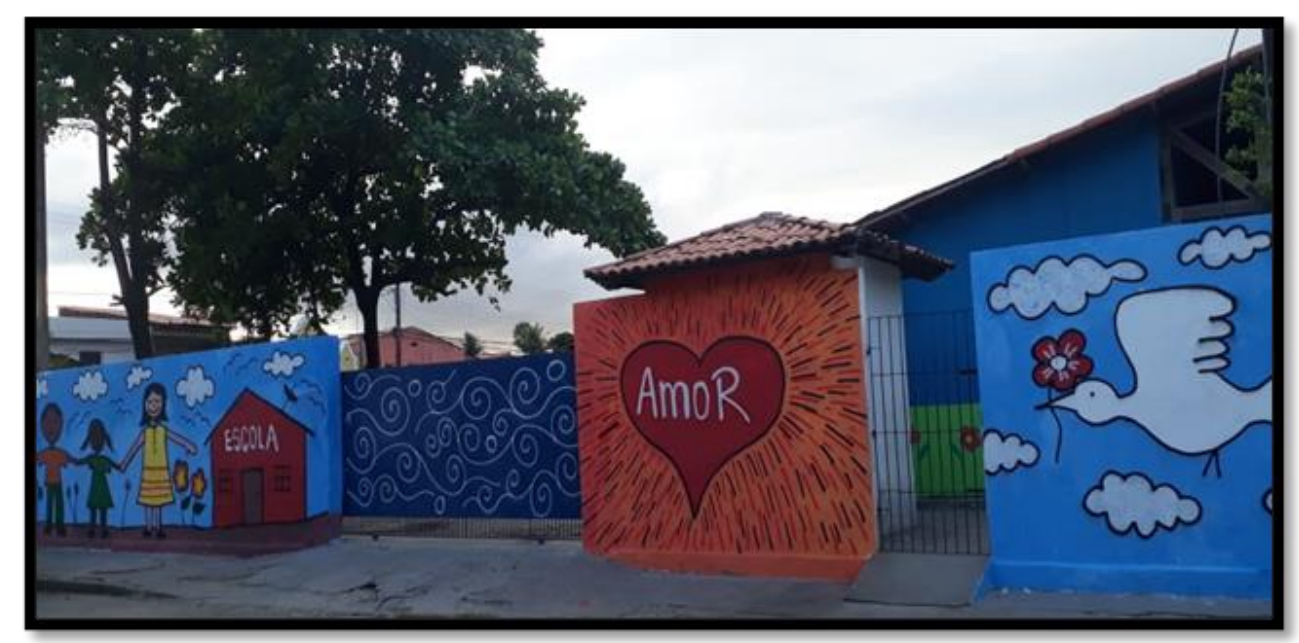

Fonte: Disponível em: http://www.emamericobarreira.online/, 2020. 
Atualmente, dispõe de três turnos de funcionamento: Manhã, tarde e noite nos seguimentos dos anos finais de $6^{\circ}$ ao $9^{\circ}$ ano com 24 turmas. Durante o ensino noturno conta com os níveis / modalidades de ensino que funcionam da EJA $1^{\circ}$ Segmento (I e II) - 02 Turmas: EJA I - Equivalente ao $1^{\circ}, 2^{\circ}$ e $3^{\circ}$ anos e EJA II - Equivalente ao $4^{\circ}$ e $5^{\circ}$ anos. Também o EJA $2^{\circ}$ Segmento (III e IV) - 02 Turmas: EJA III - Equivalente ao $6^{\circ}$ e $7^{\circ}$ anos. EJA IV - Equivalente ao $8^{\circ}$ e $9^{\circ}$ anos.

Durante o mês de março os professores da Escola E. M. Professor Américo Barreira acompanhavam as notícias de casos do Covid-19 em todo Brasil. Por ser um tema de importante relevância nacional e internacional.

$\mathrm{Na}$ semana que antecedeu o isolamento social houve a elaboração por parte dos docentes de geografia, atividades presenciais na sala de aula voltada para a temática do Covid-19. Visando informações sobre pandemia na história da humanidade, contaminação, prevenção e demais temas em todas as séries dos anos finais do $6^{\circ}$ ao $9^{\circ}$ ano e esclarecer eventuais dúvidas sobre o Covid-19.

Por conta de todos esses fatores a escola seja um importante instrumento de garantir informações e conhecimento de qualidade e ensinar os alunos, para que possam pesquisar e selecionar as informações de fontes confiáveis e a partir delas construir análises, reflexões e conhecimentos. Para Lima et al. (2018);

Diante das transformações técnicas e tecnológicas pelas quais passam a sociedade, as escolas e o processo de ensino e aprendizagem têm sido desafiados diária e cotidianamente a desenvolver metodologias que desperte no aluno a curiosidade e os instigue a questionar as informações que estão largamente disponíveis nos meios de comunicação, notadamente os de massa (LIMA; DA SILVA; DE ARAÚJO, 2018).

Pensando nisso, as aulas de geografia do $6^{\circ}$ ao $9^{\circ}$ ano, aconteceram inicialmente com uma exposição oral do professor de geografia de caráter informativo relacionando as notícias no Brasil e no mundo sobre a Pandemia conceituando o fenômeno e desenvolvendo perguntas sobre o tema, utilizando o método de tempestade de ideias no quadro para colher os conhecimentos prévios dos alunos e dúvidas sobre o assunto. Posteriormente, a partir da nuvem de ideias foram anotados os principais questionamentos e passado um documentário: Pandemia disponível no canal do YouTube da History Latinoamérica sobre a história das pandemias no mundo.

Ao final do vídeo os alunos em grupos buscaram responder as perguntas e comentar o que mais acharam interessante, respondendo principalmente qual a relação que encontram do 
vídeo com o momento atual que estavam vivendo no seu cotidiano e nas notícias do Brasil e no mundo, ao final da atividade uma pessoa do grupo sintetizava as respostas da equipe e compartilhava com a sala.

As aulas foram planejadas observando as competências específicas para os anos finais em geografia observado as unidades temáticas o sujeito e seu lugar no mundo e as conexões e escalas previstas na Base Nacional Comum Curricular (BNCC) trabalhando principalmente os aspectos humanos de saúde, higienização, prevenção, aspectos climáticos, migrações, fronteiras, e dinâmicas e decisões políticas dos países afetados pelo Covid-19 do global ao local tendo como material de trabalho as notícias de jornais televisivos e internet.

Após o decreto do Governo do Estado do Ceará definido que a partir do dia 19 de março as escolas seriam fechadas a gestão da escola iniciou o trabalho de um novo modelo de ensino observando a realidade e comunidade escolar. Sobre o sistema de Home Office ou de Trabalho Remoto instituído pelo Governo do Estado em parceria com a Secretaria Municipal de Educação de Fortaleza (SME) que previa as orientações de como seria o ensino não presencial adotado pelas escolas da rede municipal. Silva (2020) destaca que:

\footnotetext{
Os educadores, como todos os profissionais que alteraram seu local de trabalho, de presencial à Home office, precisam se cuidar, pois o fenômeno corrente tende a mudar o comportamento social. Contudo, não é o fim. Assim, cabe aos educadores se apropriarem das experiências disponíveis nesse tempo para analisar racionalmente alternativas para intervir de forma eficaz no processo de ensino e aprendizagem dos alunos. (SILVA, 2020)
}

Deu-se início a formação de grupos de Whatsapp nos quais seriam usados inicialmente para passar às principais informações para as famílias sobre o ocorrido. Na semana seguinte ao decreto de isolamento social no Ceará, os professores organizaram-se para a elaboração de atividades que seriam enviadas para os familiares e alunos nos grupos das turmas.

Inicialmente existia um único grupo dos líderes de sala para adicionarem os contatos dos colegas e repassarem as atividades. Posteriormente veio o trabalho da gestão junto a secretaria da escola para formação de grupos por turmas, além de adicionar os contatos dos pais ou responsáveis dos alunos nos arquivos do aluno na escola.

O critério utilizado pela gestão da escola foi a rede social Whatsapp verificada como a melhor opção para atingir o maior número de pessoas, visando não prejudicar o acesso à educação dos alunos e facilitar a comunicação e ao alcance dos conteúdos definidos também pelas diretrizes como flexibilizados. Assim, a implementação dessa alternativa, aparentemente mais viável, foi amplamente discutida sob pena de configurar prejuízos à aprendizagem dos 
Ensino de Geografia em tempos de Pandemia: vivências na Escola Municipal Professor Américo Barreira, Fortaleza - CE

Rebeka Carvalho Macêdo; Kaline da Silva Moreira

estudantes que, por exemplo, alguns estudantes que não tinham o devido acesso a tais recursos pelas diferentes realidades sociais da população brasileira. (DE OLIVEIRA; DE SOUZA, 2020)

Em abril de 2020, deu-se início as reuniões virtuais, que ocorrem de maneira semanal e posteiormente quinzenal, por meio do aplicativo de vídeo conferência ZOOM da gestão com docentes para atualizar informações da rede municipal e relatar como estavam ocorrendo as interações com alunos e familiares nos grupos.

Nas reuniões (Figura 3), os temas de pauta eram voltados para atualizações da rede municipal sobre as diretrizes de sugestões como proceder o ensino não presencial. Optou-se pelo modelo de atividades digitadas para o envio dos conteúdos de geografia e demais disciplinas visando o acesso para alguns alunos ainda não tinham recebido o material livro didático.

Figura 3: Reunião da Gestão com os Docentes no aplicativo ZOOM.

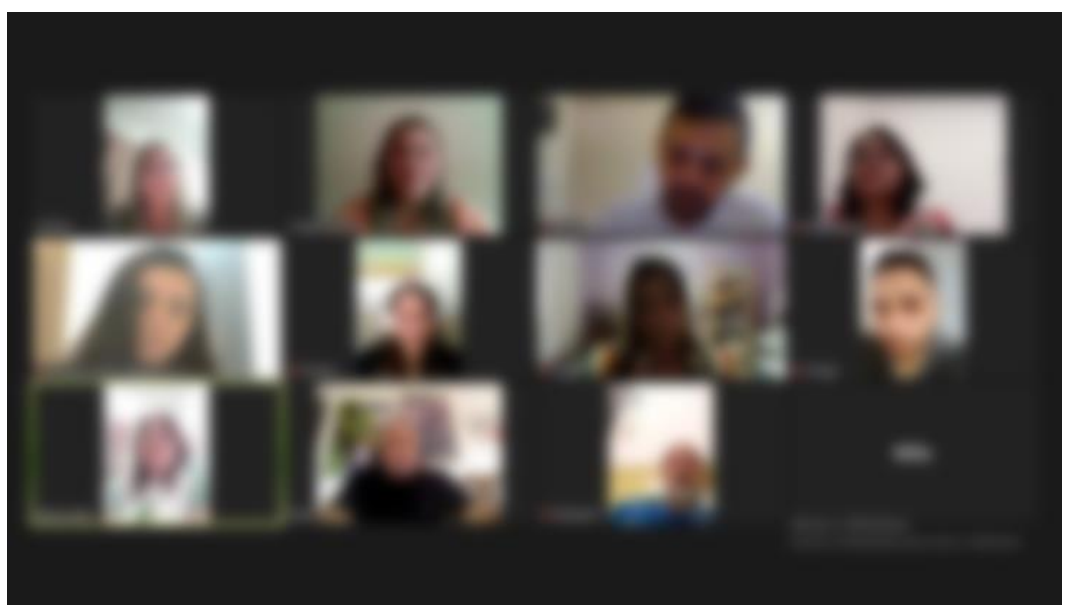

Fonte: MACÊDO, 2020.

Os professores de geografia tiveram que se adaptar e esse novo modelo de trabalho Home Office utilizando seus próprios matérias e instrumentos pessoais para realização do trabalho e mantendo sua carga horária de trabalho remoto semelhante ao presencial garantindo a disponibilidade para interações a serviço da escola e alunos no horário comercial de trabalho no regime de $100 \mathrm{~h}$ ou $200 \mathrm{~h}$ semanais.

As orientações municipais apontaram o regime de trabalho remoto "Visando cumprir com a carga horária mínima anual exigida na legislação vigente, devem adotar como estratégia de ensino e aprendizagem, durante esse regime especial, de caráter excepcional, a orientação de estudos com atividades domiciliares" (SME, 2020) e os planejamentos dos professores continuaram junto a elaboração de atividades e momentos de interação virtual nos 
grupos das turmas para recebimento das atividades, tirar dúvidas e auxiliar os alunos nos conteúdos propostos e na elaboração de videoaulas.

A escola conta com dois professores de geografia que dividiram as turmas por série tendo um professor de geografia ficado para auxiliar as turmas de $6^{\circ}$ e $9^{\circ}$ anos e outro professor as turmas de $7^{\circ}$ e $8^{\circ}$ anos visando facilitar as interações e acompanhar com maior qualidade as turmas. Ficou decidido também como sugestão da rede municipal a elaboração de atividades com conteúdos flexibilizados para facilitar a resolução e o acesso dos alunos de maneira mais autônoma visando as dificuldades para alguns estudantes e professores da não interação presencial na prática do ensino-aprendizagem.

No mês de abril de 2020, tivemos avanços na questão da interação com os alunos pois a gestão da escola teve um auxílio através de um familiar da coordenadora da escola, que criou um site, não tendo nenhum custo para a escola, para disponibilizar uma plataforma oficial de interação de alunos e professores e atuar como um banco de dados para dispor as atividades, vídeos, avisos entre outros com acesso a qualquer momento por meio de logins diferenciados para alunos e professores e mesmo assim continuou-se mantendo as interações de professores e alunos nos grupos de Whatsapp.

Sabemos que nem todas as escolas públicas de periferia terão acesso a um site como plataforma digital oficial da própria escola. A realidade é que muitas escolas públicas os docentes optaram por utilizar plataformas digitais de empresas privadas gratuitas com Google Classroom, grupos no Whatsapp, grupos no Facebook, páginas no Instagram, Padlet, ZOOM, YouTube entre outras.

Segundo Coelho (2020) essa não é a realidade nas escolas públicas do Brasil, podendo, em vez de alinhar uma educação sem fronteiras, tender para a exclusão dos alunos de escolas públicas, a começar por aqueles que moram nas periferias, no campo ou em cidades distinta do local da escola.

Ao final do mês de maio de 2020 a gestão escolar em virtude das dificuldades de encontrar os contatos atualizados dos pais e alunos ainda não havia alcançado o acesso de $100 \%$ dos alunos por turmas nos grupos dando início a uma nova estratégia envolvendo os professores, o projeto de tutoria virtual. Nesse projeto cada professor ficaria responsável por uma turma, para motivação dos alunos aos estudos e tentar inseri-los nas plataformas para que todos os estudantes tenham acesso e também descobrir os principais motivos de não participarem dos grupos, interações e entrega de atividades. 
Ensino de Geografia em tempos de Pandemia: vivências na Escola Municipal Professor Américo Barreira, Fortaleza - CE

Rebeka Carvalho Macêdo; Kaline da Silva Moreira

\section{Resultados e discurssões do ensino - aprendizagem remoto de geografia.}

Durante o ensino remoto de geografia os professores elaboram seus planejamentos das aulas baseados nas orientações da SME (Secretaria Municipal de Educação) visando a elaboração de atividades domiciliares com conteúdos flexibilizados. Os docentes optaram por continuar os conteúdos programáticos elaborados no planeamento anual do início do ano letivo de 2020 propondo atividades adaptadas que garantissem a autonomia de elaboração por parte dos alunos e a orientação da realização, explicações dos conteúdos através dos grupos de WhatsApp, disponibilizando textos e questionários digitados, áudios e por meio de videoaulas.

Segundo Lima et al. (2018) no século XXI é inegável o crescente aumento do uso de smartfones, redes sociais e internet no nosso cotidiano e isso está muito presente na escola. Antes da Pandemia os professores travavam uma batalha pela atenção dos alunos nas aulas presencias devido ao uso indevido dos celulares durante a aula sem uma finalidade pedagógica. Hoje sabemos que o caminho é incluir esses instrumentos na prática do ensino com finalidade educacional. Visto que:

\footnotetext{
No século XXI, o acesso facilitado e cada vez maior à uma série de instrumentos tecnológicos e redes de informação, exige da abordagem do ensino de Geografia, a necessidade premente de acompanhar as transformações tecnológicas que crianças, jovens e adultos hoje dominam, tais como smathphones, jogos eletrônicos, possibilidades de informações mais rápidas e interativas considerando o Youtube, Netflix e as redes sociais como Twitter, Instagram e Facebook (LIMA; DA SILVA; DE ARAÚJO, 2018).
}

À medida que os decretos prologavam o isolamento, durante o período de abril a junho, as interações com o uso das TIC's (Tecnologias Digitais da Informação e Comunicação) aumentaram consideravelmente onde "a mediação pedagógica quanto essas tecnologias fazem toda diferença, pois mais do que saber utilizar esses recursos, é saber como usá-los de forma dialética e em prol da educação.” (MARQUES, 2020 p. 36).

A necessidade da maior interação nos grupos sobre os conteúdos e dúvidas dos conteúdos geográficos contribuiu para novas e rápidas adaptações para a busca de outras ferramentas e plataformas deixando visível a importância das tecnologias para garantir o acesso ao ensino durante o isolamento social. Visto que;

As TIC'S são vitais para o protagonismo dos estudantes neste projeto, pois para torná-lo produtivo e estimulante é necessário fazer uso de outras estratégias e metodologias, como por exemplo, menos aulas expositivas e mais metodologias ativas e trabalhos socializados que tenham o aluno como peça-chave na construção do conhecimento. Por se tratarem de nativos digitais, estes possuem grande destreza 
em manusear as tecnologias para a pesquisa e produção de conteúdos. (SILVA, 2019).

Porém apenas o uso das tecnologias e metodologias ativas não garante a qualidade do aprendizado significativo dos conteúdos de geografia, é preciso um compromisso por parte dos estudantes. "A aprendizagem significativa é um processo no qual o indivíduo relaciona uma nova informação de forma não arbitrária e substantiva com aspectos relevantes presentes na sua estrutura cognitiva" (AUSUBEL et al, 1980).

Segundo Preti (2005), ao refletir sobre autonomia dos estudantes numa distância transacional contribui ao afirmar que o aluno, neste novo cenário, deve assumir para si a responsabilidade da sua própria formação, tendo autonomia e disciplina para o estudo compromissos de todo o processo educativo. (PRETRI, 2005 apud MARQUES, 2020)

Essa autonomia estudantil tem relação com a capacidade do aluno de gerir seu tempo dentro da sua rotina domiciliar com o auxílio da família e garantir sua aprendizagem estando abertos as propostas apresentadas pelos professores e que também devem ser estimulantes e motivadora. Caso contrário, os alunos nativos digitais se perdem na infinidade de distrações que a internet pode oferecer. Na concepção de Correia e Shinaigger:

\footnotetext{
As redes atraem os estudantes. Eles gostam de navegar na rede, de descobrir endereços novos, de divulgar suas descobertas, de se comunicar com outros colegas. Mas também podem perder-se entre tantas conexões possíveis, tendo dificuldade em escolher o que é significativo, em fazer relações, em questionar afirmações problemáticas. (CORREIA; SHINAIGGER, 2020 p. 24).
}

Nesse processo de ensino remoto é importante ressaltar o papel desenvolvido pelos indivíduos envolvidos. Sendo estes observados neste trabalho como: a gestão escolar, a familía, os docentes e estudantes, pois só a partir da comprrensão desses papeis podemos compreender melhor os principais desafios encontrados para o ensino de geografia remoto.

A gestão escolar teve o papel de unir esforços e articular os profissionais da escola, famílias e alunos instruindo e repassando as diretrizes e orientações da Secretaria Municipal de Ensino por meio de reuniões virtuais e de pensar junto aos docentes de maneira democrática estratégias de como melhor poderia ser desenvolvido o trabalho em Home Office e acesso as atividades escolares dentro da realidade da comunidade escolar.

O papel da família, nesse processo de ensino não presencial, é de suma importância auxiliando o trabalho dos professores em motivar os alunos a criar uma rotina de estudo em casa, para participarem das interações virtuais com os professores, estarem atentos aos avisos 
escolares, darem apoio psicológico e emocional nesses tempos onde a interação e a socialização dos alunos está reduzida o convívio social presencial.

Porém na prática existe é "a angústia que afeta as famílias que, agora isoladas em casa, precisam transformar suas salas, quando não o único cômodo comum de uma residência, no local do acontecimento da escola e suas atividades. Mais ainda, precisam ser os professores locais dos próprios filhos" (DE SANTANA FILHO, 2020). Essa realidade está presente na comunidade do Parque Genibaú afetando o desempenho da aprendizagem dos alunos.

O papel do docente de geografia no ensino não presencial é planejar atividades domiciliares flexibilizadas garantindo a qualidade de mediar e orientar virtualmente a elaboração das atividades promovendo a interação, tirando dúvidas sobre o tema da atividade e prática da mesma. Elaborar videoaulas e editá-las e lançar em plataformas acessíveis aos alunos da escola. Também cabe ao professor ser um motivador das atividades propostas, receber e registrar as devolutivas dos alunos e avaliar a aprendizagem por meio das atividades enviadas pelos alunos via foto, interação online ou e-mail.

O papel dos estudantes durante o ensino remoto é garantir o compromisso com sua aprendizagem realizando uma rotina de estudos domiciliar seguindo o cronograma de estudos proposto pela escola e a realização das atividades propostas, compartilhando dúvidas e informações na qual venham contribuir com a sua aprendizagem e os demais colegas nos grupos de interação e site da escola.

As atividades iniciais desenvolvidas na disciplina de geografia foram priorizando o livro didático tendo em vista uma ferramenta que a grande maioria dos alunos tinha o aceso imediato. Porém, apenas o maior número não é suficiente, é preciso uma estratégia para contemplar a todos, visto que, alguns alunos ainda não haviam recebido o kit de livros da rede municipal, então os docentes de geografia juntamente com os outros profissionais optaram pela elaboração de atividade domiciliares digitadas. Visto que:

\footnotetext{
A urgência para que já nas primeiras semanas os professores, agora assumido tarefas a partir de suas casas, realizassem a transposição de seus planejamentos para plataformas virtuais e recursos pela internet conduz à reprodução pura e simples da exposição oral presencial para a repetição à distância das explicações e exercícios.(DE SANTANA FILHO, 2020).
}

Posterior as atividades digitadas as aulas de geografia passaram a ser gravadas em casa através do aplicativo OBS Studio pelo notebook e editadas no aplicativo Kinemaster pelo smartfone e disponibilizadas no canal do YouTube pessoal do docente onde os links de acesso as aulas junto a atividade digitada direcionada ao conteúdo da videoaula eram nos grupos de 
Ensino de Geografia em tempos de Pandemia: vivências na Escola Municipal Professor Américo Barreira, Fortaleza - CE

Rebeka Carvalho Macêdo; Kaline da Silva Moreira

Whatsapp nas turmas de $7^{\circ} \mathrm{A}, \mathrm{B}$ e C; $8^{\circ} \mathrm{A}, \mathrm{B}$ e $\mathrm{C}$ no horário da manhã e $7^{\circ} \mathrm{A}, \mathrm{B}$ e $\mathrm{C} ; 8^{\circ} \mathrm{A}, \mathrm{B}$ e C no horário da tarde totalizando a realização dessa prática por 12 turmas dos anos finais.

Optou-se por atividades domiciliares dos conteúdos geográficos ligados ao cotidiano dos estudantes com experiências que pudessem materializar os conhecimentos apreendidos de maneira virtual como a elaboração de vídeos pelos próprios alunos motivando-os a compartilhar nos grupos, sendo que os resultados das suas atividades e explicando e mostrando de forma eles compreenderam do assunto. "É esta visão da contribuição da geografia escolar na formação dos sujeitos que melhor pode contribuir, hoje, para que se problematize o contexto atual, o isolamento, a pandemia e o lugar do ser humano no mundo produzido por ele (DE SANTANA FILHO, 2020).

As respostas das devolutivas dos alunos em participação e entrega dessas atividades que envolvi videoaulas com estudos dirigidos tiveram resultados de engajamento e participação dos alunos mais positivas no quesito de avalição da aprendizagem, porém negativos no número de estudantes que entregaram as atividades, levando a temática da evasão escolar onde "a pandemia da COVID-19 criou amplas repercussões negativas nos diferentes Sistemas Nacionais de Educação que tendem a reproduzir um ciclo vicioso de desigualdades." (SENHORAS, 2020).

Tal asserção é uma realidade para muitas crianças, já que esse isolamento social também promove maior visibilidade da desigualdade existente no país, não apenas em relação ao acesso à internet ou aos recursos que lhe deem esta conexão, mas também uma desigualdade social, cultural e educacional, pois, por óbvio, os mesmos recursos das escolas privadas não possuem os alunos das escolas públicas, principalmente nos interiores municipais, onde a escassez de recursos financeiros e de pessoal é ainda mais severa. (SILVA, 2020).

Desde o início do ensino remoto surgiram dúvidas e questionamentos por parte dos docentes sobre a preocupação com a qualidade do ensino de geografia durante a Pandemia e que tipo de metodologias passaríamos a adaptar que melhor tivéssemos como resultados essa qualidade visando buscar um melhor engajamento dos alunos de maneira virtual.

Os principais desafios encontrados para o ensino de geografia remoto foi a dificuldade de conseguir o contato dos alunos e pais para inseri-los nos grupos de interação. Alguns contatos fornecidos nas pastas de documentos dos estudantes encontravam-se desatualizados. Para sanar esse problema a gestão fez um intenso trabalho de levantamento de dados nas pastas escolares até mesmo visitas domiciliares para garantir o acesso do aluno ao ensino remoto. 
Outro problema relacionado a vulnerabilidade socioeconômica dos alunos foi o acesso à internet e a smartphones e computadores por parte dos estudantes para a participação das interações e aulas, onde muito desses alunos da rede básica de ensino usam aparelhos telefônicos de terceiros (pais, avós, vizinhos, amigos) não garantindo a interação de maneira direta entre professor e aluno como no ensino presencial. Esse problema faz parte da realidade brasileira e está longe de ser solucionado.

Segundo De Santana Filho (2020) a realidade das escolas do Rio de Janeiro não é diferente das escolas de Fortaleza onde "Em relatos recentes encontramos informações de famílias apelando para parentes e vizinhos no acesso à internet para que atividades, testes e material de envio obrigatório pelos estudantes pudessem ocorrer." (DE SANTANA FILHO, 2020)

Associados os conteúdos curriculares tratados das aulas de geografia buscou-se trabalhar também conteúdos socioemocionais com atividades que deram abertura aos alunos exporem por meio de desenhos, textos, áudios e vídeos e como estavam vivenciando e sentido nesse momento de isolamento social em suas casas.

Embora que os avanços tecnológicos com mais instrumentos e aplicativos e novas técnicas estão cada vez mais modernos e pareçam cada vez mais acessíveis, durante o período da pandemia, mesmo com a grande dependência do uso dessas tecnologias por parte da maioria dos estudantes e pais ou responsáveis foi possível ver o enorme abismo causado pela desigualdade social, e uma forte exclusão digital e até mesmo a evasão dos alunos na participação das atividades domiciliares por falta de apoio e estruturação familiar, pobreza, e por ajudarem no trabalho dos pais, a realização de tarefas domiciliares, por cuidarem de parentes e muitas outras dificuldades para manterem uma rotina de estudos, uma realidade que já era comum no ensino presencial e se tornou mais evidente no ensino remoto.

Todos motivos elencados foram relatados pelos pais ou pelos alunos nos grupos de interação e passados para gestão e docentes como fatores que são desmotivadores de se manter esse modelo e ensino não presencial, principalmente nos anos finais da rede básica pública de ensino. Estes problemas afetam diretamente a qualidade de ensino-aprendizagem de geografia gerando questionamentos aos docentes de como vamos sanar essa lacuna no retorno as atividades presenciais e quais serão as garantias ao acesso dos conteúdos aos alunos prejudicados que não participaram do ensino não presencial. 
marcante no processo de avaliação definido por este (OLIVEIRA; SOUZA, 2020, p. 21).

Sabemos que uma gama de profissionais no Brasil trabalha no modelo presencial e que possuem ainda dificuldades técnicas com o uso das ferramentas tecnológicas. Para além disso, o acesso à internet e aos conteúdos não chega de maneira igualitária para todos. Existe um fator que precisa ser considerado que é a dificuldade dos professores a se adaptar as tecnologias e para os educandos problemas de vulnerabilidade social, exclusão digital e evasão escolar.

Senhoras (2020) destaca a evasão escolar como alguns dos efeitos críticos da pandemia do COVID-19 sobre a educação formam que merecem destaque se referem aos impactos negativos manifestado pelo comprometimento do processo de ensino-aprendizagem e merecem ser pensados estratégias de planejamento e esforço junto de governantes, gestores, professores, alunos e familiares para a resolução de problemas para a normalização dos ciclos escolares no médio prazo.

\section{Considerações finais}

A realidade em escala local que se apresenta para o professor de geografia durante o período de isolamento social de todos os seguimentos, seja da rede particular ou pública, é a do trabalho remoto. Gerando inúmeras reflexões, sobre a (re) significação do seu papel e práticas metodológicas, dentre elas, suas percepções sobre a precarização na qualidade do trabalho e da aprendizagem dos alunos nos âmbitos ensino-aprendizagem e técnicas, quando muitos destes docentes não se encontravam preparados e qualificados para esse novo modelo de trabalho, o Home Office.

Ao longo do trabalho foi possível observar como os docentes vivenciam as consequências da repentina instrumentalização dos professores de geografia que rapidamente tiveram que aprender ou reaprender a utilizar meios tecnológicos sendo novas ferramentas, programas de edição de vídeos, interações nas principais plataformas digitais de ensino e redes socias.

É possível identificar, nesse cenário pandêmico que as práticas metodológicas e técnicas de muitos professores de geografia que tiveram que mudar e se adaptar rapidamente. O trabalho que antes era presencial passou a ser remoto. Os alunos tiveram que acessar os conteúdos escolares por diferentes aplicativos ou plataformas e adaptar-se a uma nova rotina de vida em isolamento, muito diferente da rotina escolar presencial. 
Apontamos também os principais desafios do ensino de geografia remoto relatados pelos familiares e alunos como motivos da evasão dos estudantes na participação das atividades de interação virtual. Dentre eles as dificuldades socioeconômicas presentes na comunidade escolar: desigualdade social, falta de acesso a ferramentas e a internet ocasionando a exclusão digital dos alunos menos favorecidos, desestruturação familiar, trabalho doméstico entre outros.

Podemos considerar como hipótese para futuros trabalhos que a pandemia do Covid19 é como um divisor de águas na maneira de pensar a educação e nas práticas metodológicas do ensino de geografia, nos levando a refletir sobre a (re)significação do papel do professor de geografia e suas práticas metodológicas a partir do ponto de vista das suas percepções sobre propostas para melhorar a qualidade do ensino de geografia apontando uso das tecnologias e as metodologias ativas previstas na Base Nacional Comum Curricular (BNCC), como uma proposta de melhorar as práticas pedagógicas de ensino de geografia nesse novo cenário global.

Como sugestões de novas investigações pode-se realizar pesquisas de cunho qualiquantitativo com a elaboração de entrevistas, questionários e gráficos que demonstre na fala dos alunos e professores as dificuldades e sobre a falta do acesso à internet e uso das tecnologias na rede básica de ensino.

\section{Referências}

ARAUJO, R. S. Letramento digital e educação. In: MERCADO. L. P. L. (Org.). Percursos na formação de professores com tecnologias da informação e comunicação na educação. Maceió: Edufal, 2007. Disponível em: $<$ http://www.repositorio.ufal.br/bitstream/riufal/1329.pdf $>$. Acesso em: 01 jun. 2020.

ASSOCIAÇÃO BRASILEIRA DE NORMAS TÉCNICAS. NBR 10520: apresentação de citações em documentos. Rio de Janeiro, 2002.

BRASIL, MEC. Base Nacional Comum Curricular. Versão final. 2018. Disponível em: basenacionalcomum.mec.br. Acesso em: 20/08/2020.

BRASIL. Ministério da Educação. CNE aprova diretrizes para escolas durante a pandemia. Brasília: junho, 2020. Disponível em: $<$ http://portal.mec.gov.br/busca-geral/12-noticias/acoesprogramas-e-projetos-637152388/89051-cne-aprova-diretrizes-para-escolas-durante-a-pandemia>

Acesso em: 08 jun. 2020.

BURGESS, Simon; SIEVERTSEN, Hans Henrik. Schools, skills, and learning: The impact of COVID-19 on education. VoxEu. org, v. 1, 2020. 
Ensino de Geografia em tempos de Pandemia: vivências na Escola Municipal Professor Américo Barreira, Fortaleza - CE

Rebeka Carvalho Macêdo; Kaline da Silva Moreira

COELHO, M. "Por uma Educação sem Fronteiras e em Tempos de Pandemia-Democrática, Pública e de Qualidade". Journal of Social Pedagogy, vol. 9, n. 1, 2020.

CORREA, Edinelson Saldanha; SHINAIGGER, Thiago Rocha. Smartphone como alicerce de metodologias ativas no ensino e aprendizagem da geografia. Educationis, v. 8, n. 2, p. 19-28, 2020.

DAVIS, M. “A crise do coronavírus é um monstro alimentado pelo capitalismo". In: DAVIS, M. et.al. (orgs.). Coronavírus e a luta de classes. Brasil: Terra sem Amos, 2020.

DE OLIVEIRA, Hudson do Vale; DE SOUZA, Francimeire Sales. Do conteúdo programático ao sistema de avaliação: reflexões educacionais em tempos de pandemia (COVID-19). Boletim de Conjuntura (BOCA), v. 2, n. 5, p. 15-24, 2020.

DE SANTANA FILHO, Manoel Martins. EDUCAÇÃO GEOGRÁFICA, DOCÊNCIA E O CONTEXTO DA PANDEMIA COVID-19. Revista Tamoios, v. 16, n. 1, 2020.

DEWEY, J. Vida e educação. Recife: Fundação Joaquim Nabuco, Editora Massangana, 2010. Disponível em: < http://www.dominiopublico.gov.br/download/texto/me4677.pdf> Acesso em 01 jun. 2020.

DOURADO, Nathan Pereira. A CRISE DO CAPITALISMO EM TEMPOS-ESPAÇOS DE PANDEMIA. Boletim de Conjuntura (BOCA), v. 3, n. 7, p. 09-15, 2020.

GADOTTI, M. Perspectivas atuais da educação. São Paulo em Perspectiva, v. 14, n. 2. abr./jun. 2000. Disponível em: 〈https://www.scielo.br/pdf/spp/v14n2/9782.pdf >. Acesso em: 01 jun. 2020.

G1. Serviços afetados pelo coronavírus no Ceará. G1 [17/03/2020]. Disponível em: $<$ https://g1.globo.com/ce/ceara/noticia/2020/03/17/coronavirus-veja-o-que-mudou-na-rotina-docearense.ghtml> Acesso: 27 jun. 2020

LAKATOS, E. M.; DE ANDRADE MARCONI, M. Metodologia científica. São Paulo: Atlas, 1991.

LEMOS, Evelyse dos Santos et al. A aprendizagem significativa: estratégias facilitadoras e avaliação. 2011. Disponível em: < http://www.if.ufrgs.br/asr/artigos/Artigo ID3/v1 n1 a2011.pdf>. Acesso em: Acesso: 27 jun. 2020.

LÉVY, P. Cibercultura. São Paulo: Editora 34, 1999.

LÉVY, P. Inteligência coletiva: para uma antropologia do ciberespaço. São Paulo: Loyola, 2007.

LOPES, C. S.; PONTUSCHKA, N. N. Mobilização e Construção de Saberes na Prática Pedagógica do Professor de Geografia. Geosaberes, v. 2, n.3, p. 89-104, 2011.

MARQUES, Ronualdo. A ressignificação da educação e o processo de ensino e aprendizagem no contexto de pandemia da COVID-19. Boletim de Conjuntura (BOCA), v. 3, n. 7, p. 31-46, 2020.

OLIVEIRA, C. D. M. de, SILVA, L.L.O, ROCHA, M. da S., ALVES, E. R., MALHEIRO, D.R. Dimensões essenciais da docência em situações de crise. Projeto de Pesquisa. Fortaleza: maio, 2020. Disponível em: http://www.lege.ufc.br/images/stories/arquivos/pesquisa\%20leges\%20doc\%EAncia\%20em\%20quaren tena.pdf > Acesso em: 08 jun. 2020.

OLIVEIRA, Victor Hugo Nedel. O PAPEL DA GEOGRAFIA DIANTE DA PANDEMIA DA COVID-19. Boletim de Conjuntura (BOCA), v. 3, n. 7, p. 80-84, 2020. 
Ensino de Geografia em tempos de Pandemia: vivências na Escola Municipal Professor Américo Barreira, Fortaleza - CE

Rebeka Carvalho Macêdo; Kaline da Silva Moreira

OPAS. Organização Pan-Americana da Saúde. Covid-19: Materiais de Comunicação. Brasil: abril, 2020.

Disponível

em:

$<$ https://www.paho.org/bra/index.php?option=com_content\&view=article\&id=6130:covid-19-

materiais-de-comunicacao\&Itemid=0> Acesso em 08 jun. 2020.

SANTOS, D. "Hipocrisia à distância: a escola finge que está educando e os pais fingem que os filhos estão aprendendo". Revista Bula [s/d]. Disponível em: . Acesso em: 14/04/2020.

SCHNEIDER, Michele Domingos; ZANETTE, Elisa Netto; CECHELLA, Nara Cristine Thomé Palácios. Relato de experiência: metodologia de aprendizagem baseada em projeto, em curso de graduação a distância. Criar Educação, 2016.

SECRETARIA MUNICIPAL DE EDUCAÇÃO. SME divulga, em diálogo com Sindiute, orientações sobre o trabalho domiciliar para profissionais da educação e desenvolvimento de atividades pelos alunos durante a suspensão das aulas. Disponível em: <http://intranet.sme.fortaleza.ce.gov.br/index.php/lista-de-noticias/5774-sme-divulga-em-dialogocom-sindiute-orientacoes-sobre-o-trabalho-domiciliar-para-profissionais-da-educacao-edesenvolvimento-de-atividades-pelos-alunos-durante-a-suspensao-das-aulas $>$. Acesso em: 03 jun. 2020 .

SENHORAS, E. M. "Coronavírus e Educação: Análise dos Impactos Assimétricos". Boletim de Conjuntura (BOCA), vol. 2, n. 5, 2020.

SENHORAS, Eloi Martins. Coronavírus e o papel das pandemias na história humana. Boletim de Conjuntura (BOCA), v. 1, n. 1, p. 31-34, 2020.

SILVA, Lorena et al. EDUCADORES FRENTE À PANDEMIA: DILEMAS E INTERVENÇÕES ALTERNATIVAS PARA COORDENADORES E DOCENTES. Boletim de Conjuntura (BOCA), v. 3, n. 7, p. 53-64, 2020. 